\title{
A Case of Urachal Malacoplakia that Seems Like Urachal Cancer
}

\author{
Osman İnci ${ }^{1}$, Ebru Taştekin ${ }^{2}$, Hakan Gençhellaç³, Özcan Arabac1 ${ }^{1}$, Serap İşler ${ }^{2}$, İrfan Hüseyin Atakan ${ }^{1}$
}

\author{
${ }^{1}$ Department of Urology, Trakya University Faculty of Medicine, Edirne, Turkey \\ ${ }^{2}$ Department of Pathology, Trakya University Faculty of Medicine, Edirne, Turkey \\ ${ }^{3}$ Department of Radiology, Trakya University Faculty of Medicine, Edirne, Turkey
}

Background: Urachal masses observed in adults should be considered malignant unless they are confuted. It is very difficult to differentiate between malignant or benign lesions, including especially calcified foci and solid areas.

Case Report: Our case was a 63-year-old male patient who was diagnosed as Behçet's Disease 26 years ago. Upon clinical examination, he was also diagnosed with adenocarcinoma of prostate. He was examined by computerized tomography to define the stage of prostatic adenocarcinoma. The existence of a hypodense multiseptated cystic lesion with irregular margins and solid areas located between anterosuperior of bladder and umbilicus was reported. Hence, the lesion was evaluated as urachal carcinoma and locally advanced prostate cancer by the urooncology council. Resection of the mass, partial cystectomy and pelvic lymphadenectomy were performed as one of the surgical approach options in urachal carcinoma. After pathological examination, the mass was diagnosed as malakoplakia and metastasis of prostate adenocarcinoma was also detected in the right obdurator lymph nodule. In the literature, case reports of urachal malakoplakia are extremely rare. It is also interesting to note the absence of specific clinical symptoms for the urachal mass and the existence of concomitant adenocarcinoma in our case.

Conclusion: Malakoplakia can only be diagnosed by pathological examination. Particularly, urachal malakoplakia should also be taken into consideration in the differential diagnosis of lesions which include solid areas and are located in the urachus.

Keywords: Michaelis Gutmann bodies, urachal malacoplakia, urachal malacoplakia mimicking cancer
Ninety percent of urachal masses are adjacent to the bladder and those lesions that contain solid or solid-cystic areas should be principally considered urachal carcinoma. A total of 22 extravesical locations were reported out of 25 urachal carcinoma cases (1). Similarly, in the analysis of 33 cases of urachal mass, 22 of them were reported as malignant, 5 as an abscess, 3 as a cyst and 2 as malakoplakia (2). An adult who was operated upon with the pre-diagnosis of urachus cancer (3) and also a child who was pre-diagnosed with urachal anomaly (4) were diagnosed as malakoplakia of the bladder after pathological examination. Malakoplakia is a different type of inflammatory reaction of unknown etiology. It is rarely seen and is diagnosed with the help of histopathological examination (5). Case reports on urachal malakoplakia in the literature are very rare. Therefore, here, we point out the existence of the extremely rare anatomical localization of the malakoplakia, as in our case, and emphasize that Malakoplakia should also be considered in the differential diagnosis of urachal masses. 


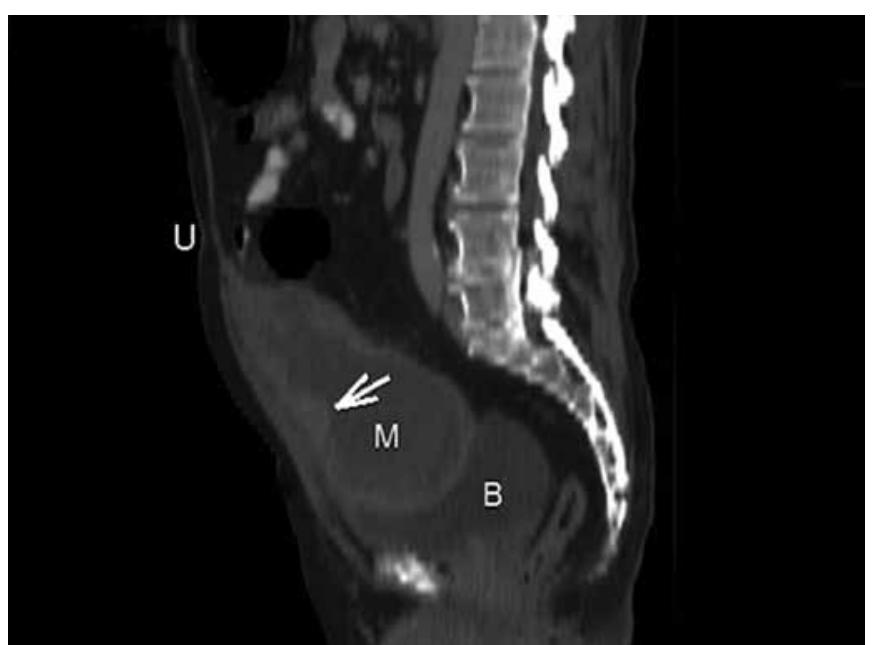

FIG. 1. Mass lesion that extended from anterosuperior bladder to umbilicus, had $10^{*} 12 \mathrm{~cm}$ dimensions in the widest part, containing multiseptas, thick-walled, solid areas (arrow). (U: Umbilicus, M: Mass, B: Bladder)

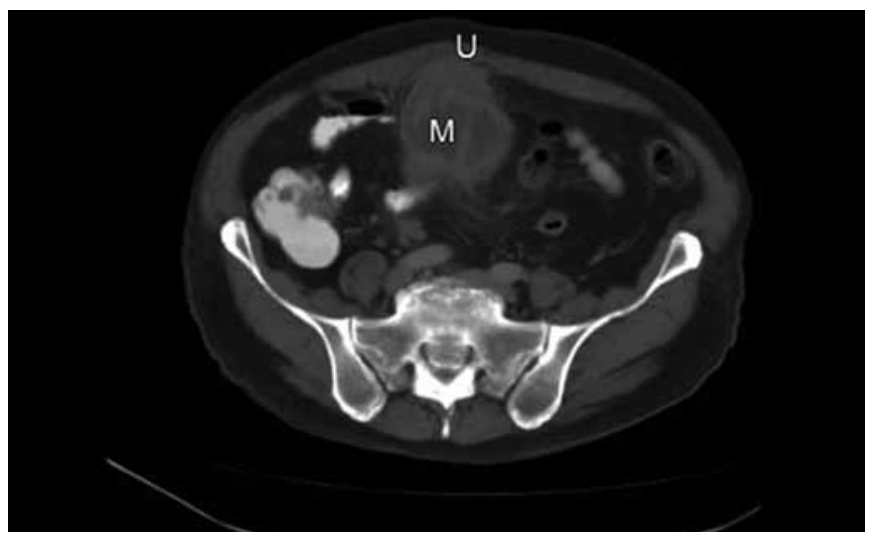

FIG. 2. Hypodense cystic lesion that caused heterogeneity in surrounding fatty tissue. (U: Umbilicus, M: Mass, B: Bladder)

\section{CASE PRESENTATION}

A 63-year-old patient complaining of lower urinary tract symptoms (LUTS) was examined by our polyclinic. Prostate biopsy was performed when serum prostate specific antigen (PSA) levels were determined to be high (total PSA=37.8). The disease was diagnosed as prostate adenocarcinoma with Gleason score 4+4:8/10. Common rigidity in the prostate and asymmetry in the right lobe was detected by the help of digital rectal examination.

In 1986, the patient was diagnosed with Behçet's disease. Vision loss in the right eye (90\%) and in the left eye (60\%) was identified due to lack of regular treatment. In a computed tomography report, the mass was defined as cystic character with multiseptas, a $12 \mathrm{~cm}$ craniocaudal length $(10 * 12 \mathrm{~cm}$ dimensions in its widest part), and irregular margins that extended from the anterosuperior bladder to the umbilicus, causing

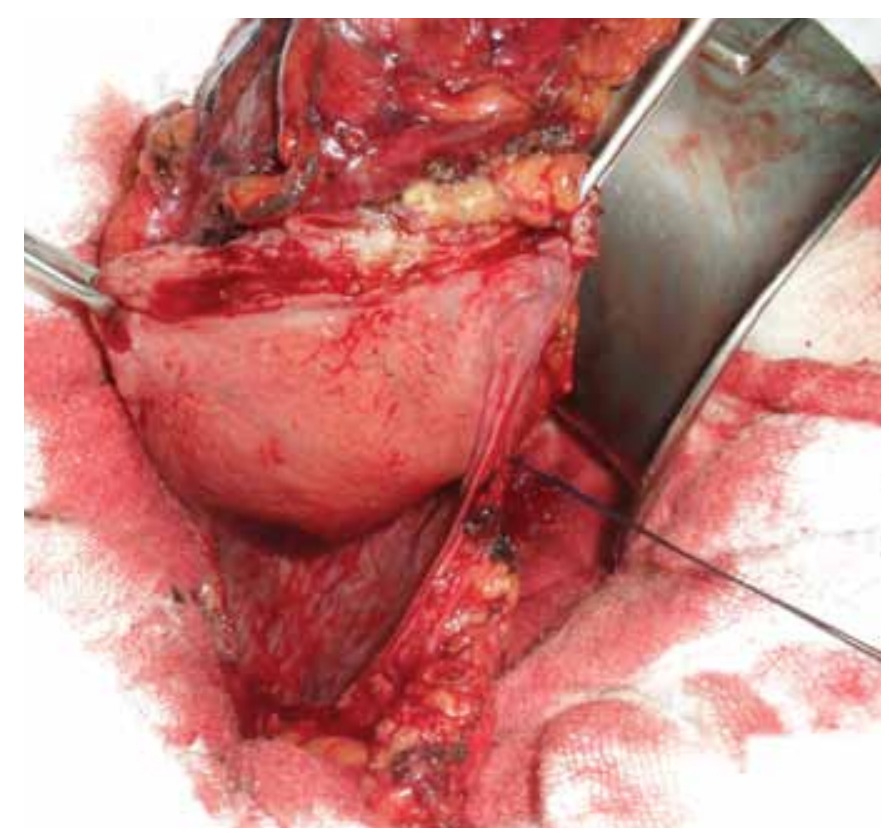

FIG. 3. During surgery, there was no pathology in the mucosa of the bladder

heterogeneity in the surrounding fatty tissue (Figures 1,2). Urachal malignancy was primarily considered in radiological reports.

Peripheral focal heterogeneity in the posterior part of the prostate gland was also reported in the computed tomography report.

We informed the patient in the matter of surgical operation and possible complications, and also took consent from the patient with regard to publishing a case report of this pathology. Urachal tumor resection + partial cystectomy and pelvic lymphadenectomy were suggested by the urooncology council. During the operation, the adhesions which extended from midline anterior abdominal wall to the anterio-superior wall of the bladder were fixed. When the bladder was incised, there was no pathology in its mucosa (Figure 3). The anterosuperior wall of the bladder that adhered to the mass was resected with safety surgical margins. After incision of the mass, cystic degeneration with mid-serohemorrhagic fluid-filled, yellowgray colored nodular structures were seen (Figure 4).

A lot of histiocytes which form a mass, a lesion formed with plasma cells and lymphocytes, were examined using microscopic study. Mixed suppurating inflammation around the cyst was observed (Figures 5,6). Calcified lamellar MichaelisGutmann bodies painted with Von Kossa and Periodic Acid Shift (PAS) paints were examined (Figure 7).

Pathological diagnoses were "malakoplakia" for the mass, "metastasis from prostate adenocarcinoma" for the right obturator lymph nodule and "inflammation signs" for the appendix vermiformis. 


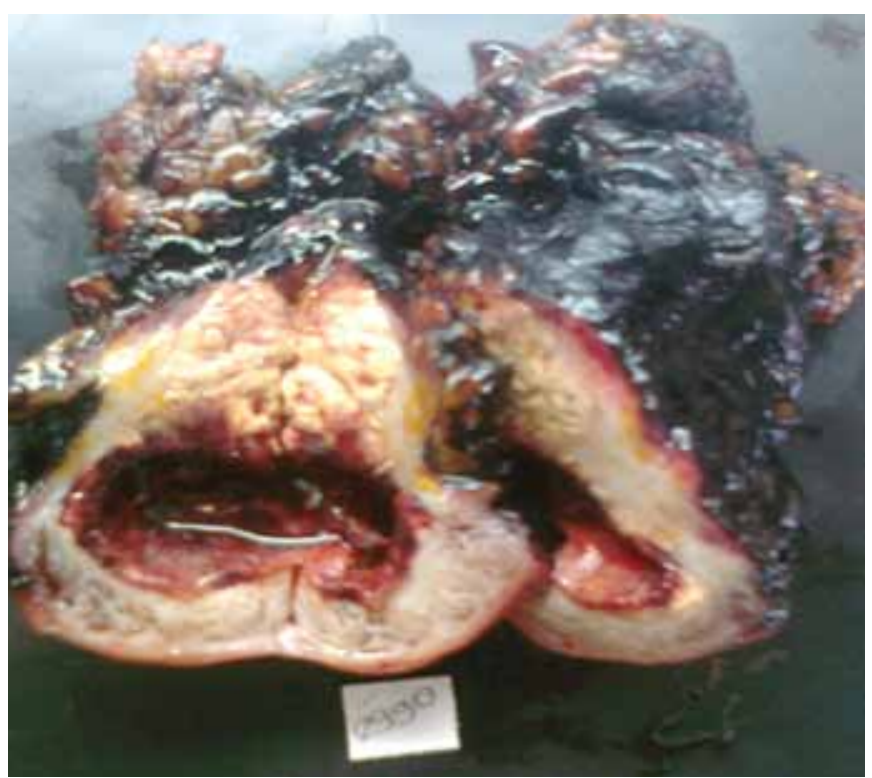

FIG. 4. When the India ink stained (for detection of surgical margins), formaldehyde locked mass was incised, cystic-degeneration structures in the middle and depletion of serohemorrhagic liquid from its lumen were seen

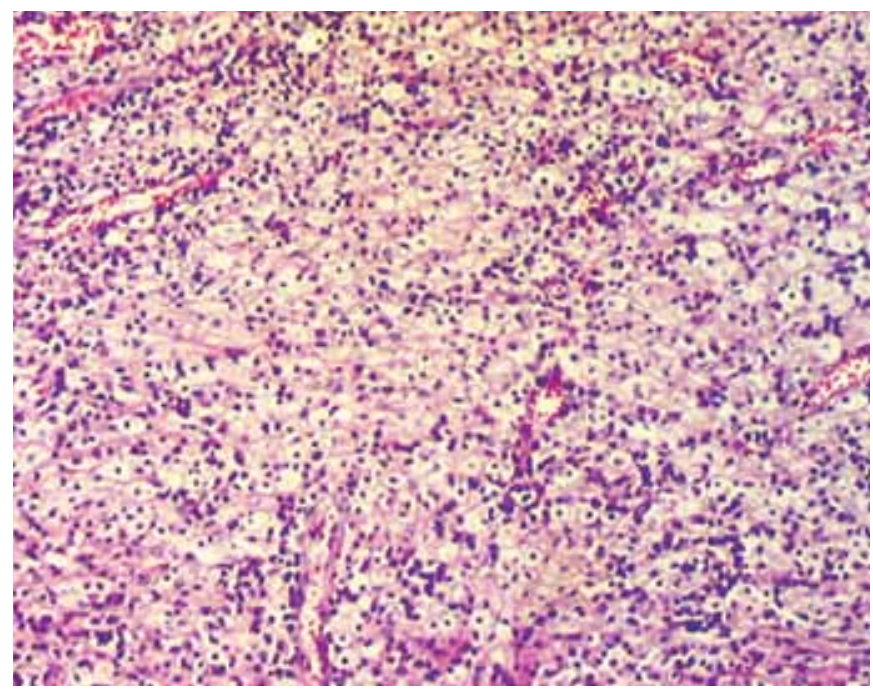

FIG. 5. Microscopy: Plenty of histiocytes concamitant plasma cells and a mixed inflammatory cell infiltration consisting of lymphocytes (HEX50) which form mass were seen

\section{DISCUSSION}

The lumen covered with the epithelium remains throughout life and urachal adenocarcinoma may develop from this epithelium. Most of the urachal masses are considered malignant. However, 2 urachal malakoplakia cases have been reported in the analysis of 33 urachal masses in adults (2). In addition, an adult who had been pre-diagnosed with urachus cancer (3) and a child who had been pre-diagnosed with urachal anomaly (4)

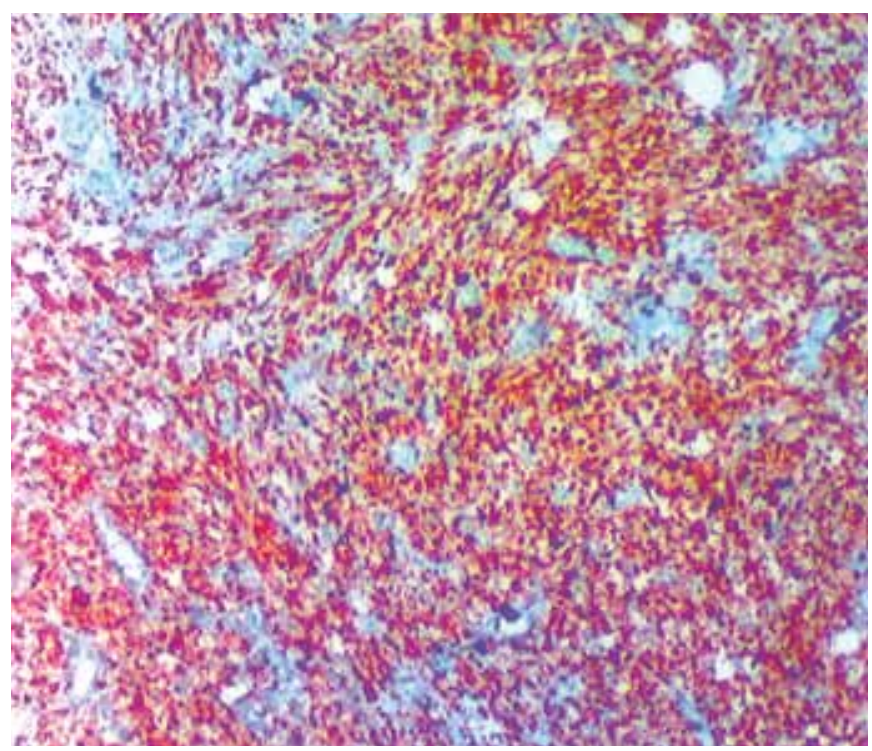

FIG. 6. Microscopy: CD68 positivity as an immunohistochemical indicator were seen on a large number of histiocytes in lesion (X50)

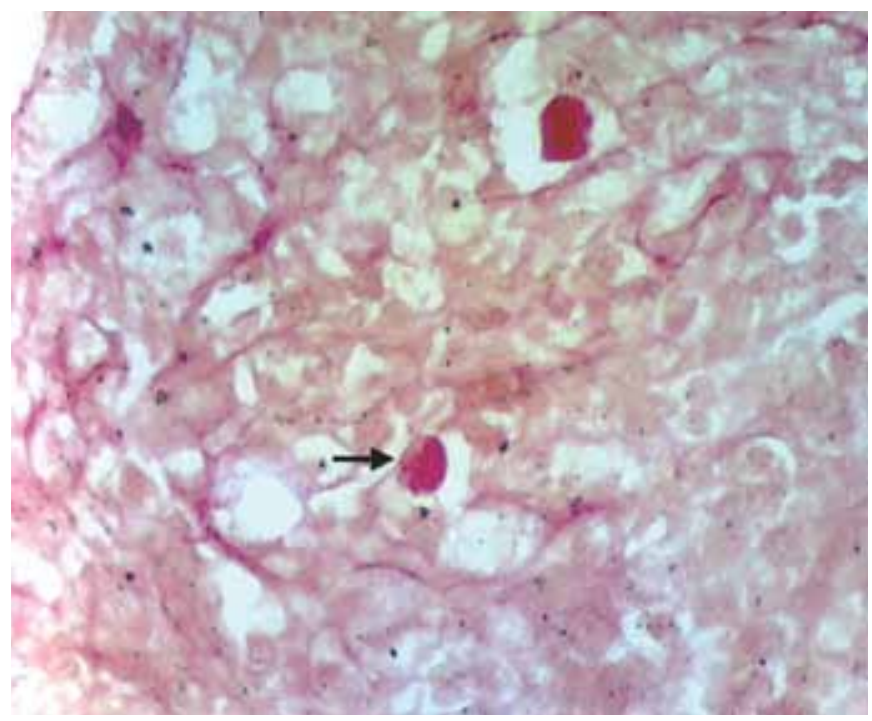

FIG. 7. Microscopy: Intracytoplasmic Michaelis Gutmann bodies (C) in the lesion (arrow) were seen (Von Kossa X400)

were diagnosed as malakoplakia of the bladder by pathology department.

Our patient had been diagnosed with Behçets Disease 26 years ago. Recently, adenocarcinoma of the prostate had been diagnosed. As for radiology, the multiseptated, thick-walled cystic lesion that consisted of solid areas and extended from anterosuperior of the bladder to the umblicus was evaluated as urachus carcinoma in computerized tomography (CT). Urachus carcinomas are seen at the junction of the bladder with the urachus and expand, pushing the demarcation line without invasion. Therefore, partial cystectomy (resection of lesion with surrounding bladder tissue) is a viable treatment 
option (6). Radical cystectomy is also recommended for the treatment of urachus cancer. It was reported that there was no significant difference between the extended partial cystectomy and radical cystectomy (7). The resection of the mass with bladder is an option in cases such as our lesion, which is not opening to the bladder lumen, and has no clear surgical margins with the bladder tissue, as well as in cases when there may be a risk of high positive surgical margins after resection of the mass. However, there is no clear evidence for urachus cancer. Frozen or excisional biopsy was not done because perforation and implantation risk is high in cystic lesions. The mass was diagnosed as malakoplakia upon pathological examination. Moreover, prostate adenocarcinoma metastases were detected by the examination of the right obturator lymph node. The differential diagnosis between urachal carcinoma and malakoplakia in the localization of urachus was only carried out histopathologically.

As in our case, mass excision with surrounding bladder tissue is the appropriate approach to urachal mass lesions that cannot be diagnosed definitely by pathology during operation, that do not open to the lumen of the bladder and that do not have certain borders with the bladder.

Ethics Committee Approval: N/A.

Informed Consent: Written informed consent was obtained from the patient who participated in this study.

Peer-review: Externally peer-reviewed.

Author contributions: Concept -İ.O; Design - İ.O.; Supervision - İ.O, T.E, Resource - İ.O, T.E, A.Ö; Materials - T.E, G.H, İ.S; Data
Collection\&/or Processing - O.İ, T.E, A.Ö, İ.S, A.İ, G.H; Analysis\&/ or Interpretation - İ.O, T.E, A.Ö, İ.S, A.İ, G.H; Literature Search İ.O, T.E, A.Ö, İ.S, A.İ, G.H; Writing - İ.O, A.Ö.; Critical Reviews - İ.O, T.E, A.Ö, İ.S, A.İ, G.H.

Conflict of Interest: No conflict of interest was declared by the authors.

Financial Disclosure: The authors declared that this study has received no financial support.

\section{REFERENCES}

1. Thali-Schwap CM, Woodward PJ, Wagner BJ. Computed tomografic appearance of urachal adenocarcinoma: review of 25 cases. Eur Radiol 2005;15:79-84. [CrossRef]

2. Tian J, Ma JH, Li CL, Xiao ZD. Urachal mass in adult. Clinical analysis of 33 cases. Zhonghua Yi Xue Za Zhi 2008;25:88:820-2.

3. Park KW, Seo IY, Rim JS. Vesical malacoplakia misdiagnosed as urachal cancer. Korean J Urol 200;43:177-9.

4. Debie B, Cosyns J-P, Feyaerts A. Opsomer RJ; Tombal B; Van Cangh P, et al. Malacoplakie chez I'enfant. Urologia Pediatrique (progres en urologie) 2005;15:511-3.

5. Mukha RP, Kumar S, Ramani MK, Kekre NS. Isolated Malacoplakia of the bladder: a rare case report and review of literature. Int Urol Nephrol 2010;42:349-50. [CrossRef]

6. Herr HW. Urachal carcinoma: the case for extended partial cystectomi. J Urol 1994;151:365-6.

7. Pinthus JH, Haddad R, Trahtenberg J, Holowaty E, Bowler J, Herzenberg AJ, et.al. J Urol 2006;175:2042-7. [CrossRef] 